\title{
Do griô ao vovô: o contador de histórias tradicional africano e suas representações na literatura infantil ${ }^{1}$
}

\author{
Celso Sisto Silva ${ }^{2}$
}

Resumo: Após um levantamento das funções sociais exercidas pelo tradicional contador de histórias africano (genealogista, guerreiro ou testemunha, historiador, porta-voz, diplomata, mediador de conflitos, tradutor-intérprete, instrumentista, compositor, cantor, professor, exortador da coragem em situações de guerra o competições esportivas, transmissor de notícias, condutor de cerimônias, emissário familiar em situações de corte, casamento, tomadas de posse e funerais), o trabalho se propõe a mostrar como esse artista da palavra vai perdendo suas funções na representação que ganha em várias obras de literatura destinadas ao leitor criança, assumindo desde uma voz oculta e às vezes pouco localizável até transformar-se na figura afetuosa do vovô que conta histórias. O artigo faz menção aos registros escritos dos contos africanos de transmissão oral nas coletâneas de contos populares de Silvio Romero, Nina Rodrigues, Arthur Ramos, Câmara Cascudo e Monteiro Lobato em que já se pode reconhecer o "esvaziamento" de algumas funções do narrador oral tradicional, para por fim, demonstrar como autores contemporâneos da literatura infantil, como Rogério Andrade Barbosa e Ondjaki, mais especificamente nos livros da coleção Bichos da África (editora Ática) e A menina das cinco tranças (editora Companhia das Letrinhas) lidam com essa representação. O objetivo maior desta pesquisa é mostrar como a literatura infantil tem, de algum modo, contribuído para dar visibilidade às literaturas africanas de transmissão oral no quadro da cultura brasileira. O corpo teórico que sustenta o trabalho está vinculado às obras do pesquisador americano Thomas A. Hale e do antropólogo Sory Câmara, no que se refere às funções do narrador de histórias tradicional. Para refletir sobre a transferência da espetacularidade contida na performance oral dos narradores tradicionais africanos para o texto escrito, valemo-nos das pesquisas de Frederico Augusto Garcia Fernandes. Para mencionar o conceito de nação, pertencimento e comunidades imaginadas, valemo-nos ainda das ideias de Stuart Hall.

Palavras-chave: griô; oralidade; reconto; literatura infantil; autores contemporâneos.

Summary: After a survey of the social functions performed by traditional african storyteller (genealogist, warrior or witness, historian, spokesperson, diplomat, conflict mediator, translator, interpreter, musician, composer, singer, teacher, exhorter of courage in war situations or sports

\footnotetext{
${ }^{1}$ Texto apresentado oralmente no III seminário brasileiro de poéticas orais/comunicação oral, em Porto Alegre (RS), em 17 de setembro de 2013.

${ }^{2}$ Celso Sisto é Doutor em Teoria da Literatura (PUCRS). Atualmente é professor Adjunto da Faculdade de Letras e Faculdade de Educação - FALE e FACED/PUCRS. Endereço profissional: PUCRS - Av. Ipiranga, 6681 - Faculdade de Letras - Prédio 8 - sala 223 - Partenon - Porto Alegre/RS - CEP 90619-900 - Fone 33203528/ramal 4615 - celso.sisto@pucrs.br
} 
competitions, transmitter news, conductor of ceremonies, family emissary in cutting situations, marriage, takeovers and funerals), the study aims to show how this word artist will lose their functions in the representation that wins in various works of literature aimed at child readers, assuming from a hidden voice and sometimes little localizable to become the figure loving grandpa who tells stories. The article makes mention of the written records of the African tales of oral transmission in the collections of folk tales of Silvio Romero, Nina Rodrigues, Arthur Ramos, Câmara Cascudo and Monteiro Lobato in which one can already recognize the "hollowing out" of some functions of the oral narrator traditional to finally demonstrate how contemporary writers of children's literature, such as Rogério Andrade Barbosa and Ondjaki and more specifically in the books of the collection "Bichos da África" (published by Ática) and Ynari, a menina das cinco tranças" ( published by Companhia das Letrinhas ) deal with this representation. The main objective of this research is to show how children's literature has in some way contributed to give visibility to african literature oral transmission within the brazilian culture. The theoretical framework that underpins the work is linked to the works of American researcher Thomas A. Hale, and the anthropologist Sory Chamber, as regards the functions of the traditional storyteller. To reflect on the transfer of spectacle contained in oral performance of traditional african storytellers to the written text, we make use of research of Augusto Frederico Garcia Fernandes. To mention the concept of nation, belonging and imagined communities, yet we make use of the ideas of Stuart Hall.

Keywords: griot; orality; retelling; children's literature; contemporary authors.

Contar é ritualizar. É dar voz ao ancestral. É abrir o corpo para o sagrado. É compactuar com a visão mágica. Palavra lapidada na boca do velho griô é palavra fulgurante. Joia de mil brilhos. Pedra multifacetada. Ele tem muitos corpos: feiticeiro, bicho, caçador, sacerdote, rei, bruxo, chefe, guerreiro. O mundo começa na sua palavra. Dançar o céu, o mar, o rio, a nuvem, a sombra. Cantar os velhos ensinamentos. Narrar a natureza, o clã, a aldeia, os símbolos, a floresta, a savana, o deserto. Seu itinerário é reforçar laços. Ordenar o mundo. Perfumar a memória. Virar história.

Talvez uma bênção recaia sobre quem empresta seus ouvidos a um contador tradicional de histórias africanas. E quem conta de alguma forma abençoa seus ouvintes. Asperge sobre a audiência essa gotícula do mar sem fim das histórias.

O contador africano tem, certamente, uma ligação forte com a água. As águas dos mares, as águas dos rios, as águas das chuvas. A ação do contador tradicional é como a água do rio, farfalhando sua correnteza; é como a água do mar, obedecendo ao desígnio das marés; é como a água das chuvas, purificando 
quem a recebe. Como uma concha mágica, que se leva ao ouvido, nossa história poderia começar com a expressão "Kwesukesukela...", que quer dizer "era uma vez, há muito tempo...", dita pela voz do contador tradicional, no que a plateia responderia "cosi, cosi...", que significa, entre os povos da África do Sul, “estamos prontos para ouvir". Um jogo de interações, um jogo-ritual. Os papéis estão estabelecidos, as divisões estão delineadas: quem conta e quem ouve. Contar história será sempre esse jogo de aproximações, esse ritual que ao mesmo tempo é culto e festividade.

Os griôs, os condutores do rito do ouvir, ver, imaginar e participar, são os artesãos da palavra. São os que trabalham a palavra, burilam, dão forma, possuem essa especialidade de transformar a palavra em objeto artístico. Há registros da atuação desses artistas desde o século XIV, onde já atuavam no Império Mali. São eles os mantenedores da tradição oral africana, nos últimos setecentos anos, sem dúvida. De fato, a arte verbal dos griôs é tão antiga quanto a mais antiga das cidades da África Ocidental e as pesquisas arqueológicas podem nos fazer crer que tal arte já era mesmo praticada, na África, antes de Cristo.

Uma das coisas mais marcantes da atuação de um griô é a possibilidade de reconstruir o passado.

Uma definição rápida para o termo certamente diz que os griôs são uma espécie de historiador africano ou um contador de histórias de vilarejo. É esta, sem dúvida, uma definição parcial. Talvez mesmo injusta. Um verdadeiro griô é muito mais que isso! São muitas as teorias para explicar a origem do termo griô. A mais frequente é a que associa griô à palavra francesa guiriot, que lhe é anterior. Seu uso aparece pela primeira vez por volta de 1637.

Há, de fato, uma profusão de nomes, regiões e povos ligados ao contador de histórias tradicional africano! O que vemos, em geral é que, mudando a língua, ou o grupo ou a região, os termos para designarem esses artistas da 
palavra e da tradição mudam também. Fica aqui o registro! Aliás, em virtude do uso, o reconhecimento do termo griô é quase universal.

Os termos contadores de história ou narradores orais de fato revelam apenas um lado das atividades exercidas por um griô. Cantar e recitar louvações são as atividades mais óbvias. Portanto, as funções sociais de um griô são mais extensas do que se pensa: atuar como genealogista, conselheiro, guerreiro ou testemunha, recontar a História, servir de porta-voz, representar o governante como diplomata, mediar conflitos, interpretar e traduzir a palavra dos outros em diferentes línguas, tocar instrumentos, compor canções e melodias, cantar louvores, ensinar os estudantes, exortar os participantes numa guerra ou competição esportiva, transmitir notícias, conduzir cerimônias (como nomeações e iniciações), fazer a corte, casamentos, tomadas de posse e funerais. Todas essas funções que podiam ser desempenhadas pelos griôs, sofreram modificações nos dias de hoje. O maior desafio é exatamente transformar esse tecido verbal em algo duradouro; afetar o ouvinte de modo inigualável para que a palavra perdure, pelo menos na memória.

Hale (2007, p. 114), afirma que a força dos griôs está exatamente na combinação disso: arte poética e uma velada "eletricidade", que reside talvez no seu polissêmico e multifuncional discurso. Uma das ideias principais que atravessa a função de um griô contemporâneo é a de "ponte entre os tempos". Não só entre passado e presente, mas também no sentido prospectivo. As palavras que saem da boca de um griô podem afetar o futuro de quem lhe ouve, podem servir de modelo.

Há um texto mandinka antigo, reproduzido por Sory Câmara (1982) que diz:

\footnotetext{
As palavras muito antigas

São como as sementes

Você as semeia antes das chuvas

A terra é ressecada pelo sol

A chuva vem molhá-la
} 

A água da terra penetra nas sementes
As sementes se transformam em plantas
Então, desenvolvem as espigas de milho
Assim você, a quem acabo de dizer as Palavras Muito Antigas,
Você é a terra
Eu planto em você a semente da palavra,
Mas é preciso que a água de sua vida penetre na semente
Para que a germinação da palavra tenha lugar. ${ }^{3}$

\section{A espetacularidade da performance oral transferida para o texto escrito}

Sabemos que cada performance de um griô é uma recriação e uma reinterpretação do passado e que uma história, poderá ser recontada de muitas maneiras entre uma e outra sessão de narração oral. A palavra falada, a matériaprima dos griôs é tão trabalhada e tão moldada que eles não podem ser vistos apenas como "bardos" ou simples propagadores de histórias, senão como autores. No entanto, quando a narrativa de um griô vira texto escrito, Fica faltando a atmosfera do evento, do acontecimento em que ele está inserido, fica faltando as nuanças trazidas pelo ritmo, pela voz, pela entonação, pelo gesto, pelo movimento corporal. Fica faltando toda a sinergia que resulta dessas misturas de texto, voz, coreografia e musicalidade.

Quando os textos orais viram textos escritos, o que querem seus autores é exatamente recuperar esse poder e essa "performance" executada pelos griôs.

Esses textos orais que ganharam o registro escrito lidam e conservam as características e atributos da oralidade e da espetacularidade. Se as narrativas proferidas pelos griôs estão fundadas no dinamismo concreto da interação e se há toda uma relação direta e ininterrupta entre voz, corpo, dança, gesto, música e poesia, a proximidade entre palavra e corpo faz da atuação desses narradores tradicionais um ponto de partida importante. Essa cultura da espetacularidade verbo-gestual é, sim, a maior responsável pela fixação dessas histórias na

\footnotetext{
${ }^{3}$ Palavras de um griô mandinka, reproduzidas por Sory Camara, 1982, p. 8. Tradução nossa.
} 
memória coletiva e vice-versa, ou seja, da constante atualização dessas histórias a partir também dessa mesma memória coletiva.

É preciso lembrar que os contos tradicionais africanos atravessaram os tempos sem serem escritos. O registro escrito é coisa dos tempos modernos e foi feito, primeiramente, por não africanos (mercadores, expedicionários, missionários que atravessaram o continente durante anos), em especial americanos e europeus.

Podemos lembrar os trabalhos do antropólogo, etnólogo e explorador alemão Leo Frobenius, um dos primeiros a registrar a tradição oral sudanesa dos impérios mágicos africanos, reunidas em suas expedições antropológicas. Os mitos e lendas, as fábulas e os contos maravilhosos, os ditos e as anedotas dos primeiros povos africanos ficaram conhecidos, no Ocidente, por meio de suas coletâneas.

Podemos lembrar ainda, Silvio Romero, preocupado também em explicar a sociedade brasileira pela interação racial, com seus "Contos populares do Brasil (1885). E ainda o médico baiano Nina Rodrigues, que publicou em 1933 Os africanos no Brasil em que recolhe os contos populares iorubás, ou Artur Ramos, que em O folclore negro no Brasil (1935), estuda a contribuição mais sólida da cultura africana, já na perspectiva do folclore, para continuar a ampliar a nossa "antologia" de histórias africanas de transmissão oral. No entanto, é Monteiro Lobato, em 1937, influenciado por Silvio Romero, reúne na obra Histórias de Tia Nastácia, também uma série de contos africanos, narrados pela boca da representante negra, moradora do Sítio do Picapau Amarelo. Mas, Câmara Cascudo, em 1946 publica Contos tradicionais do Brasil. Na obra há um estudo aprofundadíssimo das fontes, que identifica e aponta uma vasta permanência de histórias africanas no universo dos contos populares brasileiros. 
É esse legado, que serve de base para o aproveitamento das histórias africanas na literatura infantil e para a fixação de muitos contos como obra dirigida ao pequeno leitor.

\section{A transformação dos griôs nos textos escritos para o leitor criança}

Os novos autores da literatura infantil (brasileira e portuguesa) publicados no Brasil vão aproveitar esse espaço transitório entre o ouvir, o recontar e o escrever sem ignorar a necessária valorização da oralidade no texto escrito. Um caminho para isso tem sido levar para o papel a figura do contador de histórias africano tradicional, mesmo que seu papel passe por uma simplificação e seu público, de coletivo, se torne individualizado.

$\mathrm{Na}$ obra "Bichos da África" (4 volumes, editora Melhoramentos, produzidos em meados dos anos 80) de Rogério Andrade Barbosa, e na obra "Ynari, a menina das cinco tranças", do angolano Ondjaki, vamos perceber bem esse aspecto. Ao afirmarmos que a literatura de transmissão oral, encontra terreno fértil na obra de Rogério Andrade Barbosa e de Ondjaki, por exemplo, estamos tentando demonstrar, como a presença dos narradores orais, são representados para o leitor brasileiro e como seu papel se propaga no texto escrito.

A despeito de uma performance oral e cênica, o contador de histórias tradicional africano, enfocado aqui como o ponto de partida do nosso trajeto de pesquisa, é um narrador surgido da práxis e, na maior parte das vezes, herdeiro direto de uma tradição familiar. Tem um repertório variado, formado ao longo do tempo e atualizado com frequencia. Está, sobretudo, "mergulhado" no que poderíamos chamar de comunidade narrativa e tem como "objeto" de trabalho, como objeto estético, histórias que são arquétipos, no sentido que lhe empresta 
Paul Zumthor (1993): histórias coletivas que preexistem e formam um conjunto virtual.

Nesse sentido, poderíamos ainda complementar a construção dessa imagem dos griôs apropriando-nos das palavras de Frederico Fernandes:

O narrador, ao atualizar o arquétipo, desempenha uma tripla função na cultura oral: narra, é o performer sensível ao auditório, já que incorpora a voz da comunidade; ouve, troca experiências com outros narradores e absorve as histórias que lhe contam; e cria, torna-se o responsável por construir um sentido para o que ouviu, bem como por atualizar isso com significantes e significados diferenciados. (2007, p. 56)

Sabemos que, guardadas as devidas proporções, o que um griô narra tem a força de representar quase uma voz sagrada, já que a comunidade lhe atribui essa aura que também é mítica, digamos assim, e por isso tem um poder e uma força incontestáveis. Ele incorpora a voz de uma comunidade de iguais, ou seja, a voz dos griôs que o formaram, que o antecederam, de quem ele herdou o ofício por laços sanguíneos. Sua performance está estritamente ligada às respostas imediatas do seu público, sem dúvida, mas ele influencia esse público muito mais do que o público o influencia. Ele é o articulador do sentido dos textos que narra, das palavras que enriquece com matizes pessoais, dos discursos que profere. Ainda que seu discurso seja investido de um caráter poético e mágico, sua atuação, embalada pela alta voltagem emocional, afeta e provoca grande impacto na audiência. Essas marcas são a garantia de que suas palavras produzirão eco.

Aproveitando essa noção, Terezinha Taborda (em $O$ vão $d a$ voz) considera que o reconto é o discurso da tradição, transformado em espetáculo, pela escrita: "teatro da ordem o qual ninguém ignora que é teatro, representação cênica de papéis e funções" (MOREIRA, 2005, p. 128). O que fazem nossos autores em questão é instaurar uma nova representatividade. O texto, "o espetáculo textual passa a dizer a própria tradição, no lugar da qual ele se coloca" (MOREIRA, 2005, p. 128). Esse espetáculo textual, na verdade, é também a representação 
intertextual, do velho griô, personagem com o qual começamos a traçar o caminho dessa pesquisa. E, com isso, também estamos considerando, como Taborda, que nesses textos o narrador transforma-se num "narrador performático" (MOREIRA, 2005, 56-69).

Em ambos os livros "Bichos da África" e "Ynari", os personagens narradores, representantes da tradição e "encarnadores" da função dos griôs Vovô Ussumane e $\mathrm{O}$ homem pequenino - são esses narradores performáticos. E ainda estão investidos de uma aura sagrada, mítica, incontestável, que se sustenta através da lembrança (são as histórias que vovô Ussumane conta para seu neto Malafi e para seus amigos, com a intenção de ilustrar um fato ocorrido na aldeia; são os exemplos vivos que "o homem pequeno e mágico" que conduz e ensina de forma prática à menina Ynari o sentido das palavras que recriam o mundo, como admiração, medo, inútil, guerra, etc.). Ambos representam uma voz coletiva. Assim, como os griôs, lidam com a plateia (o grupo de crianças em "Bichos da África"), a menina em "Ynari, a menina das cinco tranças", lida com o homem pequeno e mágico (representante de todo o saber), de forma direta, dialogada, numa interação demonstrativa (e com sentido educativo) entre perguntas e respostas. São essas relações de contar e mostrar (um que conta e outro que recebe) que fazem andar a narrativa.

São esses narradores performáticos que articulam os sentidos dos textos que narram, que usam as histórias e os feitos para compararem-nos com a vida cotidiana em que seus personagens interlocutores estão inseridos. Como faz o "homem pequeno" em "Ynari, a menina das cinco tranças":

- Tu és mágico, homem pequeno! - disse Ynari, espantada.

- Todos somos mágicos, Ynari. Aqui vais aprender que todos somos mágicos...

- Tu encantas as armas! As armas ficam de barro - disse, espantada, Ynari. - Imagino quando eles agora forem disparar! - desatou a rir a menina das cinco tranças.

- Aquelas armas já não disparam. Agora podemos utilizar a palavra "inútil".

- O que é "inútil"? - quis saber Ynari.

- É aquilo que já não é útil, ou seja, que já não serve para nada.

- Ah... Diz-me uma coisa - Ynari olhou para o homem pequeno e mágico. - Todos somos mesmo mágicos? 
- Sim, todos. Mas cada um tem que descobrir a sua magia.

- Eu queria descobrir a minha...

- Já não falta muito - disse o homem pequeno e mágico, enquanto se levantava. - Já não falta muito, Ynari (ONDJAKI, 2010. P. 19 e 20)

São as marcas da emoção, na "fala" desses narradores, que conferem às suas atuações uma alta voltagem emocional, seja na melodia das palavras, na força da linguagem, no uso de cantigas e versos, no uso de provérbios e até mesmo nos silêncios do texto, como em Bichos da África (volume 1) :

Enquanto vovô Ussumane dava uma tragada no cachimbo, a garotada conversava sobre o caçador que passara pela aldeia naquela manhã a caminho de outro povoado onde um leão estava causando grandes estragos. O que mais impressionara os meninos foram os inúmeros amuletos mágicos que o caçador trazia em volta do corpo e a espingarda, para protegê-lo das garras e dos dentes das feras

- Quando crescer quero ser um caçador profissional também - disse Malafi aos colegas.

- Mas para isso - interrompeu o avô - são necessários muitos anos de aprendizagem. O caçador profissional, homem de grande prestígio, tem que conhecer os hábitos de todos os animais da floresta, as horas que os bichos saem para comer e beber, seguir suas pegadas dia e noite e, também a arte de fazer armadilhas.

- Conte uma história sobre armadilhas - pediram os garotos em coro.

- Então escutem esta história da tartaruga... (BARBOSA, 1992, p. 11)

\section{Uma das maiores marcas desses narradores performáticos no texto escrito} é a provocação, o impacto do que diz, na audiência, os ecos deixados na palavra carregada de símbolos, como por exemplo, em Ynari, a menina das cinco tranças:

Ynari levantantou-se. Já tinham usado a palavra "despedida", agora estavam a usar as palavras "olhar para outro". Estiveram assim algum tempo.

- Quando é que nos voltamos a ver? - perguntou Ynari.

- Sempre que quisermos.

- Mas tu vives tão longe...

- Há muitas maneiras de se ir muito longe - disse o homem pequeno.

- Diz-me uma.

- Tu sabes...

- Achas que posso apanhar boleia do humbi-humbi?

- É uma ideia, ele é rápido.

- Mas eu sou tão pesada para ele...

- Mas não és pesada para o coração dele - sorriu o homem pequeno - Experimenta viajar no coração do humbi-humbi.

- Está bem, está bem - começou a correr Ynari. - Adeus, até qualquer dia!

- Adeus. Estamos juntos. Eu também sei viajar no coração do humbi-humbi. 
- Eu sei - disse Ynari. - Agora já sei!

E, como dizem os mais velhos, foi assim que aconteceu. (ONDJAKI, 2010, p. 44)

\section{Considerações finais}

O narrador coletivo (em Barbosa, Vovô Ussumane é o avô de todos) vai se tornando cada vez mais um narrador para uma audiência menor, e em $A$ África, meu pequeno Chaka (de Marie Sellier, Companhia das Letrinhas, 2006), podemos realmente perceber que é na figura do avô (com grau de parentesco de verdade!) que o autor contemporâneo tem representado o griô. Numa relação agora individualizante, íntima, muito próxima e extremamente afetiva, esse narrador-avô, recupera o papel de porta-voz do grupo e de detentor do passado, da ancestralidade, para dotar seu neto de elementos (histórias/exemplos) que o habilitem para a continuidade. Ele será depois o novo narrador, e o novo propagador das histórias e de seus personagens e antecessores, mantendo viva a memória do avô. O ciclo recomeça.

Um griô escreve no ar, com sua performance vocal, gestual, cênica, e a reação da audiência é sempre de fascínio. E a admiração se fixa na memória. E é ela que permite a manutenção dessa arte oral. São esses ecos, reverberando através do tempo, que produzem novos escritos. Por isso, todo escritor, ao escolher recontar um texto pertencente à tradição oral africana, escolhe também, de algum modo, tornar-se um griô.

Somos tentados a acreditar que esses autores têm como projeto desenhar também para o leitor (brasileiro) uma ideia de nação africana. E, para isso, também precisamos das palavras de Hall, que, lendo Benedict Anderson, afirma que "as nações não são apenas entidades políticas soberanas, mas comunidades imaginadas" (HALL, 2003, p. 26). Faz parte do jogo proposto (ou imposto?) pelo conjunto cultural, que constrói a ideia de nação, dirigir-se a um sujeito

\footnotetext{
${ }^{4}$ Segundo Stuart Hall, a expressão é de Benedict Anderson.
} 
também imaginado. Nesse processo, as manipulações são possíveis. Por isso é necessário ampliar essa visão de nação africana. E essa tem sido uma das tarefas das histórias africanas na literatura infantil.

Hall tem levantado em seus trabalhos ${ }^{5}$ uma série de questões relacionadas ao "pertencimento" e a relação com a terra de origem. Tal qual o mecanismo de atuação das comunidades transnacionais, que são rede e local da memória, essas famílias ampliadas é que fazem a ponte entre os dois lugares (idem). As histórias africanas e esses escritores aqui apresentados, também fazendo parte dessa rede de informação, dessa família ampliada, e sendo também receptáculo da memória, oferecem ao leitor brasileiro essa terra de origem, que lhe diz respeito seja na cor da pele, seja como herança nacional, de forma alargada. É a constituição de outro canal de informação, mas é também o convite para pensar a África olhando daqui para lá, com elementos trazidos de lá. É a possibilidade de uma multivisão. Estes escritores, com suas obras, também fazem essa ponte e se constituem numa outra voz, que não é a da família, que não é a voz mais próxima, mas que se configura como uma voz principalmente recente. A memória, estendida aos dias de hoje, se renova. Esse reavivamento da tradição pode ser percebido pelo leitor. A noção de "terra de origem" se renova, se amplia, se intensifica. Uma nova identidade cultural é construída e preservada também a partir da literatura infantojuvenil. Para utilizar também uma expressão explorada por Hall, podemos dizer que as "identificações associativas" com as culturas de origem permanecem fortes, mas o autor também nos lembra que, depois de gerações sucessivas, os "locais de origem" não são mais a única fonte de identificação (idem). O que fazem as histórias africanas publicadas no Brasil é potencializar, na atualidade, esses elos entre Brasil e África.

\footnotetext{
${ }^{5}$ Em especial, no texto "Pensando a diáspora: reflexões sobre a terra no exterior". In: HALL, Stuart. Da diáspora: identidades e mediações culturais. Belo Horizonte: Editora UFMG, 2003. p. 25-50.
} 


\section{Referências}

BARBOSA, Rogério Andrade. Bichos da África: lendas e fábulas, 4 volumes. 4 ed. São Paulo: Melhoramentos, 1992.

CAMARA, Sory. Gens de la parole, essai sur la condition et le rôle des griots dans la société malinké. Paris: Mouton, 1982.

FERNANDES, Frederico Augusto Garcia. A voz e o sentido: poesia oral em sincronia. São Paulo: Editora UNESP, 2007.

HALE, Thomas A. Griots and Griottes: masters of words and music. Bloomington: Indiana University Press, 2007.

HALL, Stuart. Da diáspora: identidades e mediações culturais. Belo Horizonte: Editora UFMG, 2003.

MOREIRA, Terezinha Taborda. O vão da voz: a metamorfose do narrador na ficção moçambicana. Belo Horizonte: Editora PUC Minas, Edições Horta Grande, 2005.

ONDJAKI. Ynari, a menina das cinco tranças. Ilustrações de Joana Lira. São Paulo: Companhia das Letrinhas, 2010

ZUMTHOR, Paul. A letra e a voz: a literatura medieval. São Paulo: Companhia das Letras, 1993. 